\title{
Multimodal Metaphor Patterns in Documentaries About Plastic Pollution
}

\author{
Yana Vermenych \\ Department of English Philology, V. N. Karazin Kharkiv National University, Kharkiv, Ukraine
}

\begin{abstract}
This article addresses the issue of multimodal instantiation of conceptual metaphors in documentaries about plastic pollution: A Plastic Ocean (2016) and Recycling Sham (2019). Theoretically, it departs from conceptual metaphor theory (Lakoff \& Johnson1980), extending it with the multimodal (Forceville and Urios-Aparisi 2009) and discursive (Musolff 2006) approaches to metaphor. In agreement with the latest theoretical development in this area (Ping Tang, Kelin Quan, Jianbin Zhu 2020), conceptual metaphor is viewed not as a mere correspondence between two conceptual domains, but as a condensed micronarrative that provides a rich understanding of the target domain. The research demonstrates that multimodal metaphors in the documentaries under scrutiny are capable of forming constellations that carry ideological implications, demonstrating temporal variation.
\end{abstract}

Index Terms - conceptual metaphor, documentary, mode (verbal, visual, aural), multimodality, plastic pollution

\section{INTRODUCTION}

It is hard to imagine modern life without plastic. It is everywhere: we drink and eat from it, we wear it, shop with it. It is embedded in our everyday life. However, its main property - being durable - is not only beneficial, but also causes trouble. The history of plastic dates back to 1907, when the invention of Bakelite brought about a revolution in materials by introducing a new type of plastic into world commerce (Moore, 2020). By the end of the 20th century, plastics had been found to be a persistent polluter (Moore, 2020). Plastic is mostly nonbiodegradable, and thus, it tends to persist in the environment. In the $21^{\text {st }}$ century, plastic pollution has become one of the most pressing environmental problems. The production of plastic increased exponentially, from 2.3 million tons in 1950 to 448 million tons by 2015, and it is expected to double by 2050 (Parker, 2019). Discarded plastic pollutes every corner of our planet: oceans, forests, beaches. It harms animal and human health. Since plastic pollution is most visible in developing Asian and African countries, quite a lot of people from the rest of the world still ignore this problem. However, it cannot be solved without eliminating this ignorance about the seriousness and urgency of the plastic pollution problem, which can be done, in particular, via documentaries focusing on this problem.

This article offers an analysis of documentaries about plastic pollution, A Plastic Ocean (2016) and Recycling Sham (2019). The study focuses on the use of multimodal conceptual metaphors related to the topic of plastic pollution.

Theoretically, the study departs from conceptual metaphor theory (Lakoff, Johnson, 1980, 1999), extending it by taking into consideration multimodal instantiations of conceptual metaphors (Forceville and Urios-Aparisi 2009). It also views metaphors not as a mere correspondence of target and source domains, but agrees with the latest theoretical developments in this area (Ping Tang, Kelin Quan, Jianbin Zhu 2020), as condensed micronarratives that can construct certain images.

The aim of this article is to analyze the multimodal instantiations of conceptual metaphors in the documentaries $A$ Plastic Ocean (2016) and Recycling Sham (2019), which included the following tasks: to find out the patterns of interaction of different modes in the metaphors; to bring to light the micronarrative the respective metaphoric expressions constellate into.

The results of the study demonstrate that target concepts tend to be instantiated in the verbal and / or visual modes, while instantiation of source concepts tend to be more varied and can include verbal, visual, and / or aural mode. The choice of mode also helps express more or less explicit and radical micronarrative that stands behind the metaphors.

Structurally, the article consists of six parts: (1) introduction, (2) theoretical background, (3) research methodology, (4) results, (5) discussion and (6) conclusion. The theoretical part, which follows this introduction, presents the key concepts of conceptual metaphor theory and multimodal metaphor theory. The methodological part describes the sample and process of analyzing multimodal instantiations of the metaphors in documentaries. That is followed by a presentation of results and then a discussion. The conclusion summarizes the findings and outlines prospects for further research.

\section{THEORETICAL BACKGROUND}

In conceptual metaphor theory, the conceptual metaphor is defined as a partial understanding of one concept in terms of another (Lakoff, Johnson, 1980, p. 1). The identified concept is called the target concept / domain; the concept 
involved for comparison is the conceptual source concept / domain. During the process of metaphorical mapping, some conceptual features of the source domain are mapped onto the conceptual features of the target domain (Lakoff, Johnson, 1980, p. 3). The process also entails certain inferences, or conceptual features that are not directly mentioned but are logically deduced from the conceptual metaphor (Lakoff, Johnson, 1999, p. 47). As a result, conceptual metaphors allow thinking about abstract and poorly defined concepts in terms of more concrete and better defined ones, and thus, metaphors play a central role in the perception and conceptualization of reality (Lakoff, Johnson, 1980, p. 3).

It is obvious that means of actualizing conceptual metaphors cannot be limited to linguistic ones. Conceptual metaphors can also be instantiated in non-verbal semiotic systems, or modes (Forceville, Urios-Aparisi, 2009, p. 20). In our research of ecological documentaries, we focus on the following modes: the verbal mode (written vs. spoken), the visual mode (static vs. dynamic images), the aural mode (sound vs. music). Conceptual metaphors that are embodied in different modes are called multimodal (Forceville, Urios-Aparisi, 2009, p. 24).

In our study, conceptual metaphors are viewed in the spirit of Musolff (2006) and Ping Tang, Kelin Quan, Jianbin Zhu (2020) as condensed micronarratives opposing to the usual understanding of them as correspondence between two concepts (Lakoff, Johnson, 1980). Treating conceptual metaphors in the documentaries under scrutiny helps reveal the underlying stories and the way the problem of plastic pollution is conceptualized in them, and as a result, what image of plastic pollution the viewers might have.

\section{ReSEARCH Methodology}

The empirical material was collected from two documentary films, A Plastic Ocean (2016) and Recycling Sham (2019). Both documentaries are centered on the topic of plastic pollution and have good ratings on IMDb: A Plastic Ocean - 8,0/10 and Recycling Sham - 7,4/10.

A Plastic Ocean (2016) deals with the plastic pollution in the oceans. Recycling Sham (2019) is an episode of the series 'Broken'. The series consists of 4 independent episodes, each of which tackles with a pressing problem of today. The forth episode, Recycling Sham, deals with the problem of plastic pollution, single use plastic and recycling of plastic.

The analysis included three steps: (1) identification of multimodal metaphors in the documentaries, their target, source and the modes in which they are instantiated; (2) interpretation of the metaphorical entailments; (3) explanation of the micronarratives of both documentaries.

The first step dealt with selecting multimodal instantiations of conceptual metaphors with the target related to the topic of plastic, plastic production and plastic pollution (PLASTIC, PLASTIC IN THE OCEAN, A MAN THROWING AWAY PLASTIC, RECYCLING PLASTIC, PLASTIC INDUSTRY, etc.). Then the source concept / domain of each metaphor was defined, and the semiotic modes in which they are instantiated: verbal, visual, or aural. This step also included bringing out the patterns of interaction of the modes. At the second step, metaphorical entailments were considered. Finally, at the third step, the underlying micronarratives of the two documentaries were analyzed as well as their ideological implications.

\section{RESULTS}

In the documentary "A Plastic Ocean" (2016), the understanding of the concept PLASTIC POLLUTION is structured through a couple of multimodal conceptual metaphors: PLASTIC is AN ULTIMATE WEAPON and A MAN THROWING AWAY PLASTIC is A MURDERER. The metaphors have a number of instantiations that go through the whole film, interweave with each other and create one common meaning.

The conceptual metaphor PLASTIC is AN ULTIMATE WEAPON attempts to question the way most people conceptualize plastic. We buy a plastic product or a product in plastic, we use the product and throw the plastic into the garbage bin, and we think that it is gone. However, it never goes away. It stays somewhere on the planet and dramatically harms our environment, animals on it, and in the long run, people.

This is shown throughout the film in several instantiations of the metaphor PLASTIC is AN ULTIMATE WEAPON. The first instantiation of the metaphor represents the target verbally. The film shows extracts from the TEDx talk by Tanya Streeter, a world champion free diver, who tells about her experience of free diving and how she realized that she wants "to pay the sea back". She says: "I didn't know that in the last ten years, we've made more plastic then we did in the century before that. Half of that plastic products are considered "disposable". But think about it. How can a disposable product be made of a material that's indestructible? Where does it go?" (10:55-11:21). The words suggest that plastic is not disposable, and it must go and stay somewhere after being used.

The next shots answer the question above by another instantiation of both the source and target of the metaphor. They depict a whale dying because of having eaten too much plastic that it found in the sea. Tanya continues the narration: "It's dying, taking its final breaths. It was found to have six square meters of plastic sheeting inside it. It couldn't eat and it died of malnourishment. Its digestive system was blocked and it died a terrible, painful death." $(11: 30$ - 11:58). The episode is accompanied with tragic sorrowful music. Viewers understand that the whale was murdered by plastic, or in other words, plastic is an ultimate weapon that is easily mistaken for food by marine animals, 
and it kills them. In this instantiation, the source AN ULTIMATE WEAPON is expressed in the verbal, visual and aural modes, while the target PLASTIC - in the verbal and visual ones.

After that, the documentary resorts to visual-aural instantiation of the metaphor PLASTIC is AN ULTIMATE WEAPON by depicting several sea animals trapped in different sorts of plastic $(13: 50-14: 24)$. The aural mode represents the source AN ULTIMATE WEAPON by anxious beats in the background music, which create a frightening atmosphere. In the end, the image fades into black screen, which also symbolizes death.
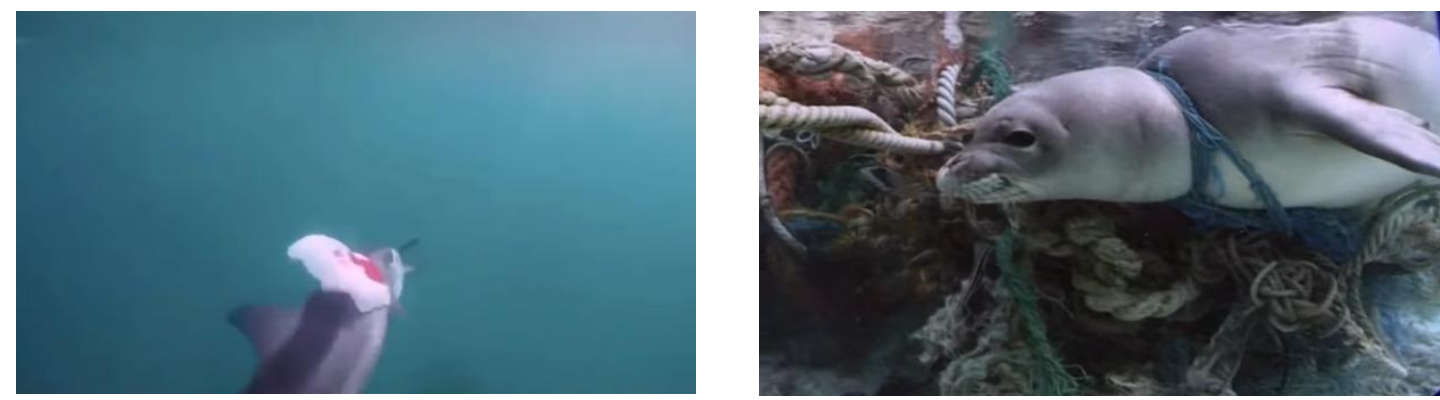

Fig. 1 Visual instantiation of the metaphor PLASTIC is AN ULTIMATE WEAPON

Next episodes bring in the second metaphor. The black screen turns into the image of a human hand unwrapping a plastic pack of bottles, and in the next seconds, this very part of the package falls down to the ocean floor (14:24 14:33). The background music is dramatic. Factoring in the previous metaphor, PLASTIC is AN ULTIMATE WEAPON, we subtly realize a new one, A MAN THROWING AWAY PLASTIC is A MURDERER. The target is expressed in the visual mode, while the source - in the aural one.

There follows another episode, which, due to the context, can be matched with both metaphors, PLASTIC is AN ULTIMATE WEAPON and A MAN THROWING AWAY PLASTIC is A MURDERER. It starts with a visual-aural introduction, where a girl takes a big plastic bottle, unscrews the plastic lid, takes the plastic ring off the bottle and throws it into the trash bin (19:02 - 19:10). After that, an oceanographer, Dr. Sylvia Earle, says: "We think that when we put something in the trash or when we just toss it from a boat or on a beach, that it "goes away". Ah! We're now free of plastic." The accepted understanding of plastic as disposable waste, the target of the first metaphor, is shown with the help of the visual and verbal modes, while the aural mode denotes the source, AN ULTIMATE WEAPON, first by tense sounds as if something bad is happening, and then by Dr. Sylvia Earle's intonation. At the same time, this is an instantiation of the metaphor A MAN THROWING AWAY PLASTIC is A MURDERER with the verbal-visual target and the aural source.

The next episode is another instantiation of the metaphor A MAN THROWING AWAY PLASTIC is A MURDERER (49:06 - 51:20). A woman is examining the insides of an albatross bird, which died because of eating too much plastic. She says: "It's quite a bit of plastic for just one little bird ... It's just a shame that every now and then they got it wrong, and got it wrong in a bad way." There are a lot of flies buzzing at the dead bird. The next shot shows a toothbrush falling into water, which then fades into the picture of a dead albatross with the open stomach and a pile of plastic in there, including a similar toothbrush. After that, another plastic bottle falls into water, and then "appears" in the dead animal. Then the plastic ring from the bottle that we have seen before also falls into water, and appears in the dead bodies of birds. Thus, we again think of the people throwing away plastic as of those who kill animals. The target of the metaphor here is expressed in the verbal and visual mode, while the source - in the visual and aural ones.
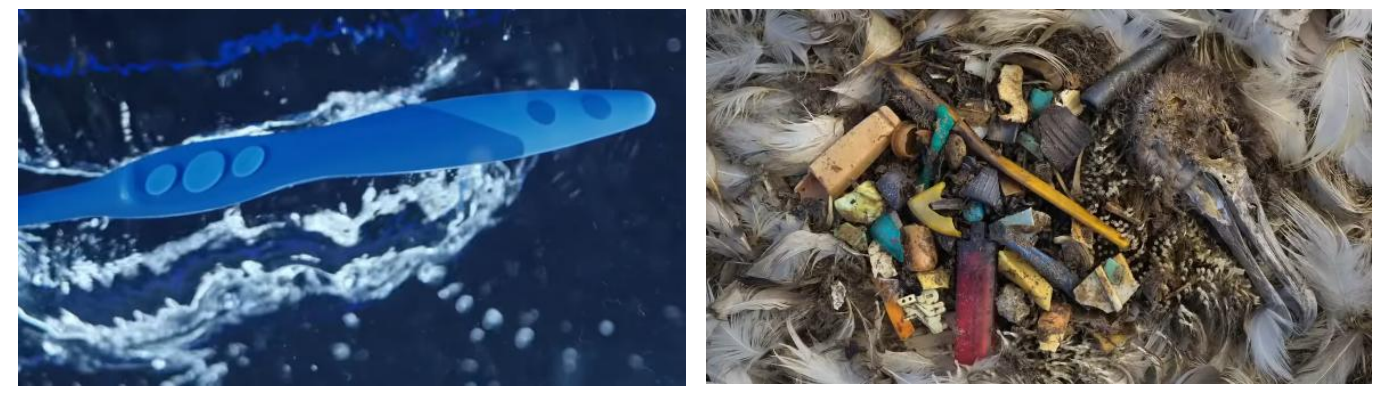

Fig. 2 Visual instantiation of the metaphor A MAN THROWING AWAY PLASTIC is A MURDERER

This way, the main message of the film, that plastic is not a disposable product and is a serious threat for the marine life, is conveyed with the help these two metaphors.

A more recent documentary on plastic pollution, Recycling Sham (2019), uses a different set of metaphors to convey a different message about the same problem of plastic pollution. It uses the following metaphors: RECYCLING PLASTIC is SHAM, PLASTIC INDUSTRY is AN ENEMY, PLASTIC POLLUTION is A MAN-MADE ENEMY, PLASTIC POLLUTION is A BURDEN FOR COMMON PEOPLE. 
First there comes an instantiation of the metaphor RECYCLING PLASTIC is SHAM (1:01 - 1:23). The visual mode shows different stages of the recycling process, expressing the conceptual target. The verbal narration goes as follows: "And the solution we've always been taught will fix it is actually a false promise. We can't recycle our way out of plastic pollution. The plastic industry has really sold us a bill of goods." This is accompanied with a disquieting background music which represents the source.

In the metaphor PLASTIC INDUSTRY is AN ENEMY, the verbal part represents both the target and source: "We're up against some of the most well-funded, ruthless, cut-throat industries on the planet. And they are actively trashing the planet." The visual part specifies which industry is meant by showing ExxonMobil plant as a representative of the industry (1:38 - 1:50). The aural mode, in the form of quiet but unsettling background music, symbolizes the source ENEMY by creating a disturbing atmosphere.
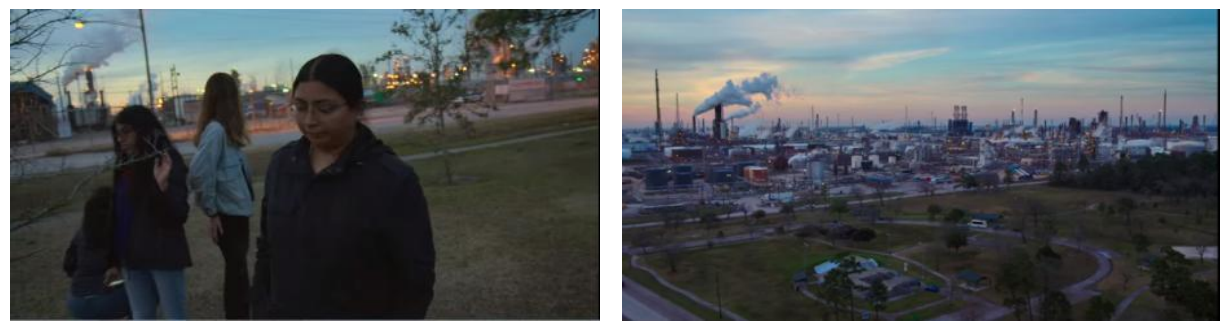

Fig. 3 Visual instantiation of the metaphor PLASTIC INDUSTRY is AN ENEMY

One of the episodes to follow presents the metaphor PLASTIC POLLUTION is A MAN-MADE ENEMY (3:11 4:20). The visual part shows piles of plastic in the streets: on the ground, falling from overfull bins, in the water. The narration says: "Why and how something so embedded in our daily lives become such a huge problem for the world? ... How we created and molded it [plastic], but even more, how it has come to mold us." The scene is accompanied with fast anxious background music. The verbal part renders the source A MAN-MADE ENEMY, as well as the aural mode that creates a frightening atmosphere. The visual part represents the target PLASTIC.

The metaphor PLASTIC POLLUTION is A BURDEN FOR COMMON PEOPLE is expressed in the interview of a woman from a developing country (29:00 - 29:40). She stands against piles of plastic waste saying: "We people bear such a big burden from the air pollution and the water pollution and just benefit to a very small group of people that our minister is saying that they already invest big money in the factory. But what happened to the environment risk and also the health risk to us? Why we bear this? Who can answer me this question? Why we bear this?". Her speech is very emotional and vehement. In this metaphor, both the target and source are expressed in two modes: verbal and visual.

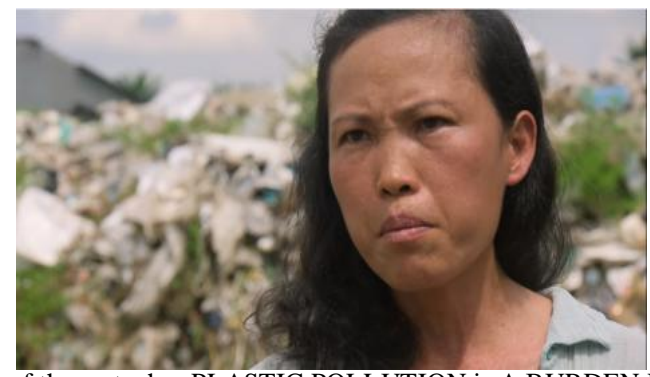

Fig. 4 Visual instantiation of the metaphor PLASTIC POLLUTION is A BURDEN FOR COMMON PEOPLE

Thus, the second documentary represents a different view on the problem of plastic pollution. It blames industry for creating plastic, exposing the false promise of recycling plastic which fools people. People suffer while industries earn money.

Both documentaries recognize the urgency of the problem. However, the first one (A Plastic Ocean, 2016) emphasizes the role of individuals by introducing the metaphor A MAN THROWING AWAY PLASTIC is A MURDERER and imputing responsibility on each individual, while the second one (Recycling Sham, 2019) highlights holds industry responsible (PLASTIC INDUSTRY is AN ENEMY), opposing it to common people who have to fight back.

\section{Discussion}

Conceptual metaphor is an instrument of thinking that plays a crucial role in the process of conceptualizing the world. It is quite widespread in documentary films on ecological problems, plastic pollution in particular, as such documentaries strive to explain the complex phenomenon by constructing a micronarrative about the problem. Conceptual metaphors in documentaries under consideration are mainly multimodal, instantiated in a combination of the verbal, visual, and / or aural modes. 


\section{A. Multimodal Metaphor Patterns}

The analysis of the multimodal metaphors in the documentaries A Plastic Ocean (2016) and Recycling Sham (2019) has shown the patterns of mode interaction that are summed up in Table 1 and Table 2 correspondingly.

TABLE 1.

Multimodal Metaphor PATTERnS In A PLASTIC OCEAN (2016)

\begin{tabular}{|l|l|}
\hline Multimodal Metaphor Pattern & Metaphor Instantiation \\
\hline verbal, visual, aural source - verbal, visual target & PLASTIC is AN ULTIMATE WEAPON (10:55 - 11:58) \\
\hline visual, aural source - visual target & PLASTIC is AN ULTIMATE WEAPON (13:50 - 14:24) \\
\hline aural source - visual target & A MAN THROWING AWAY PLASTIC is A MURDERER (14:24 - 14:33) \\
\hline aural source - verbal, visual target & PLASTIC is AN ULTIMATE WEAPON (19:02 - 19:10); A MAN THROWING AWAY \\
& PLASTIC is A MURDERER (19:02 - 19:10) \\
\hline visual, aural source - verbal, visual target & A MAN THROWING AWAY PLASTIC is A MURDERER (49:06 - 51:20) \\
\hline
\end{tabular}

Two main conceptual metaphors of the documentary A Plastic Ocean (2016) are PLASTIC is AN ULTIMATE WEAPON and A MAN THROWING AWAY PLASTIC is A MURDERER. As we can see from the patterns, the targets of these metaphors, PLASTIC and A MAN THROWING AWAY PLASTIC, are instantiated mostly in a combination of the verbal and visual modes. This accounts for the fact that documentaries usually try to explore their theme explicitly, and this one is not an exception. Thus, the target concepts, which denote plastic pollution, are explicitly designated in both the verbal and visual mode.

On the contrary, the sources, AN ULTIMATE WEAPON and A MURDERER, are mainly expressed in the aural and visual mode. In most cases, the predominant combination of the aural mode with the visual one in explicating concepts related to murder refers to them obliquely, in an indirect way. It creates an impression that the presenters and authors of the documentary do not call people murders or plastic an ultimate weapon. At least not verbally. However, every viewer gets this implication since it is quite strong.

In the other documentary, Recycling Sham (2019), multimodal metaphor patterns differ from those considered above.

TABLE 2

MULTIMODAL METAPHOR PATTERNS IN RECYCLING SHAM (2019)

\begin{tabular}{|l|l|}
\hline Multimodal Metaphor Pattern & Metaphor Instantiation \\
\hline verbal, aural source - visual target & RECYCLING PLASTIC is SHAM (1:01 - 1:23) \\
\hline verbal, aural source - verbal, visual target & PLASTIC INDUSTRY is AN ENEMY (1:38 - 1:50); PLASTIC POLLUTION is A \\
& MAN-MADE ENEMY $(3: 11-4: 20)$ \\
\hline verbal, visual source - verbal, visual target & PLASTIC POLLUTION is A BURDEN FOR COMMON PEOPLE (29:00 - 29:40) \\
\hline
\end{tabular}

Here the target concepts, RECYCLING PLASTIC, PLASTIC INDUSTRY, PLASTIC POLLUTION, are also explicitly expressed in a combination of the verbal and visual modes. However, the sources, SHAM, AN ENEMY, A BURDEN FOR COMMON PEOPLE, are mainly instantiated in the verbal and aural mode combination, which accounts for a more explicit expression of the source concepts, as compared to the metaphors in the previous documentary. These are not just aurally or visually implied hints, but verbalized statements.

As seen from the patterns, the representation of the targets in both documentaries is quite explicit. However, when it comes to the sources, the documentary A Plastic Ocean (2016) resorts to less explicit representation, rather implying certain metaphors without rich verbalization. Recycling Sham (2019) explicitly represents both targets and sources of the metaphors.

\section{B. Micronarrative about Plastic Pollution}

As stated above, this paper considers conceptual metaphors not as mere correspondence between source and target concepts, but as condensed micronarratives. After looking at the entailments of the metaphors in the documentaries, we have been able to single out two micronarratives.

The documentary A Plastic Ocean (2016) aims to reconceptualize the concept PLASTIC and to promote a certain image of the concept PLASTIC POLLUTION. Since its creation, plastic has been viewed as a disposable product by most people, which has led to enormous pollution. With the help of the metaphor PLASTIC is AN ULTIMATE WEAPON, the documentary questions the appropriateness of this view of plastic. The metaphor has the following entailments: plastic is not disposable, it is durable; it does not biodegrade and trashes the environment; after that a lot of animals both in water and on land are murdered with plastic waste that is mistaken for food. The metaphor creates negative polarity and understanding of plastic waste as a dangerous weapon.

The introduction of the next metaphor, A MAN THROWING AWAY PLASTIC is A MURDERER, in this documentary has the following entailments: using plastic is using a weapon; throwing away plastic is shooting; every person who uses and throws away plastic, meaning almost everybody in the world, is a murderer. This is a very radical and bold idea. However, the concept A MURDERER is not verbalized in the documentary, it is "explicitly rendered" by visual and aural representation of death.

With the help of these metaphors, the documentary places the responsibility for plastic pollution on every person in the world. By implying the idea that people are murderers of innocent animals, it also makes an appeal to people's conscience and urges them to minimize the usage of the plastic weapon. 
The documentary Recycling Sham (2019) presents another view of plastic pollution. The metaphor RECYCLING PLASTIC is SHAM has the following entailments: the idea of recycling plastic as a way to resolve the problem is a lie; plastic industry is an impostor who wants to earn more money by deceiving people. The entailment from the next metaphor, PLASTIC INDUSTRY is AN ENEMY: we have to fight with our enemy and defeat it. The next two metaphors describe the target PLASTIC POLLUTION with the sources A MAN-MADE ENEMY and A BURDEN FOR COMMON PEOPLE, and add other entailments: being deceived by plastic industry, people have created the plastic enemy that now threatens them; common people suffer from it, plastic industry earns money. All the metaphors create a negative view of the industry producing plastic. The documentary blames it for deceiving people and creating a huge problem. It urges people to fight with the main enemy, which is plastic industry.

The two documentaries have a different idea of the guilty party in the case of plastic pollution. The first one implies that usual people are murderers, while the second presents them as victims of a terrible sham. Correspondingly, different actions are required in each situation to resolve the problem. In the first case, people need to minimize the usage of plastic, while in the second, unite in the fight against plastic industry.

\section{CONCLUSION}

The analysis of the multimodal metaphor patterns in two documentaries A Plastic Ocean (2016) and Recycling Sham (2019) has shown that the target concepts are usually explicitly represented in the verbal and visual mode, as it is the aim of both documentaries to shed light on the problem of plastic pollution. A source concept might be instantiated aurally and visually when the aim of the film creators is just to imply it without naming directly; or it might be also verbalized when the creators of the documentary want to be more direct and radical in expressing a certain idea.

In the article, metaphors are also viewed as condensed micronarratives. The analyzed documentaries have different micronarratives and correspondingly, images of the plastic pollution, which might be due to the time difference between the two films. The earlier documentary of 2016, A Plastic Ocean, questions the understanding of plastic as disposable by conceptualizing it as a deadly dangerous weapon that kills animals and birds, and all people who use plastic products and then throw them away - as murderers. By using such metaphors, the documentary makes every person responsible for the problem and urges them to minimize the usage of plastic products. The later documentary of 2019, Recycling Sham, points out the issue of recycling plastic. It conceptualizes plastic industry as scammers who in pursuit of profit deceive common people, conceptualized as victims. The industry is responsible for plastic pollution and for pretending to be solving it, while common people bear this burden and they should fight back and defeat the enemy.

Different micronarratives are structured with the help of different conceptual metaphors, and, moreover, they use different multimodal patterns. The earlier film is less radical as it implies its narrative by presenting the source concepts in the aural and visual modes. The later film is more direct in expressing its narrative against the plastic industry and pushing people to fight back and not just stop using plastic products.

The prospects for further research lie in the analysis of documentaries about other ecological problems, like global warming, mega fires, etc. and the corresponding micronarratives.

\section{REFERENCES}

[1] A Plastic Ocean (2016). [Documentary]. https://www.netflix.com/title/80164032 (accessed 27/04/2021).

[2] Forceville, C. J. \& E. Urios-Aparisi. (2009). Multimodal Metaphor. New York: Mouton de Gruyter.

[3] Lakoff, G. \&M. Johnson. (1980). Metaphors We Live By. London: The University of Chicago Press.

[4] Lakoff, G., Johnson, M. (1999). Philosophy in the Flesh. New York: Basic Books.

[5] Moore, Ch. (2020). Plastic pollution. Encyclopedia Britannica. https://www.britannica.com/science/plastic-pollution. (accessed 27/04/2021)

[6] Musolff, A. (2006). Metaphor scenarios in public discourse. Metaphor and Symbol, 21(1), 23-38.

[7] Parker, L. (2019). The world's plastic pollution explained. https://www.nationalgeographic.com/environment/article/plasticpollution (accessed 27/04/2021).

[8] Recycling Sham. (2019). Broken. [Documentary]. https://www.netflix.com/title/81002391 (accessed 27/04/2021).

[9] Tang, P., Quan, K., \& Zhu, J. (2020). The Construction of China's Images through Multimodal Metaphor: A Case Study of China-related BBC Documentaries. Theory and Practice in Language Studies, 10(9), 1044. doi:10.17507/tpls.1009.05.

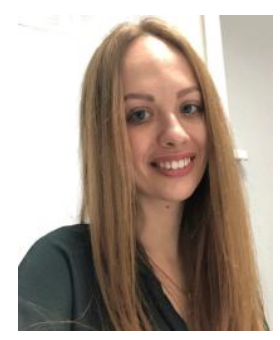

Yana Vermenych was born in Ukraine in 1994. She is a PhD student at the Department of English Philology of V. N. Karazin Kharkiv National University.

Her main research interests are in cognitive linguistics, ecolinguistics, discourse studies and multimodality. RESEARCH GATE: https://www.researchgate.net/profile/Yana_Vermenych; ORCID: https://orcid.org/00000002-2179-3906. 